\title{
DEPENDENCIA DO CRESCIMENTO DAS PLANTAS AO REGIME DE UMIDADE DO SOLO *
}

E.J. SCALOPPI**

E.C. FERRAZ ***

RESUMO

A produção de uma planta resulta do desenvolvimento integrado de inúmeros processos fisiológicos que, por sua vez, apresentam considerável individualidade nas interrelações com o meio ambiente. Neste trabatho foi observado o crescimento de plantas de batata (Solanum tuberosum L.), em condições de campo, quando submetidas a três re gimes de umidade do solo, individualizados em três estádios fenológicos. 0 desenvolvi mento vegetativo foi avaliado através de es timativas semanais da área foliar.

Os resultados mostraram que ao final do primeiro estágio (cerca de 25 dias após a emergência das plantas) o desenvolvimento vegetativo nos tratamentos irrigados quando - potencial matricial da água do solo atingia $-0,5$ bar, superou, em cerca de $34 \%$, $\bar{a}-$ quele verificado nas plantas submetidas a

* Entregue para publicação em: 17.11.1978

* Dept? de Enga. Rural, Fac. de Ciênc. Méd. e Biol. de Botucatu, SP.

*** Deptọ de Botânica, E.S.A. "Luiz de Queiroz", USP. 
déficits híbridos moderados ( $-1,0$ bar) e, em aproximadamente $80 \%$, aquelas sujeitas a déficits mais severos $(-5,0$ bares). Entretanto, a limitação do crescimento no primei ro caso, foi parcialmente recuperada após $\overline{0}$ restabelecimento de condições mais adequadas de umidade no solo, no estádio intermediário. 0 mesmo não foi verificado onde ocorreram déficits hídricos mais severos no estádio inicial, quando o crescimento foi quase irreversivelmente reduzido. A intensa desidratação imposta após a completo desenvolvimento vegetativo apressou a senes cência das plantas em relação aos tratamentos melhores supridos com agua.

\section{INTRODUÇÃO}

A identificação dos processos fisiológicos que prevalecem nos diferentes estadios de desenvolvimento das plantas cultivadas tem contribuido, significativamente, para um melhor entendimento das funções da água na planta e seus efeitos no rendimento e qualidade da produção.

Segundo KRAMER (1969) a transpiração é o fator dominante nas relações da água na planta. Este pro cesso é responsável pelo desenvolvimento dos gra= dientes de potencial que controlam o movimento da água no sistema solo-planta-atmosfera, afetando, em consequência, a razão de absorção de ãgua e ascenção da seiva. Além disso, sempre que a razão de perda exceder a de absorção, haveră o apareci mento de déficits hídricos que, geralmente, reduzem 0 crescimento (SLATYER, 1967; BOYER, 1968; CRAFTS, 1968; GATES, 1968). Por outro lado, VAADIA et al. (1961) admitem que a desidratação das plantas pode ser causada pela excessiva razão de perda, pela absorção lenta, ou pelo efeito combina do destes dois processos. Enquanto a razão de per da é controlada, principalmente, por fatores meteō rológicos, a de absorção é dependente, em grandē 
parte, do potencial da água do solo em contato com as raízes.

Uma das principais adaptações protetoras das plantas à redução da umidade consiste na habilidade em renovar as proteínas durante o período desfa vorável e restabelecê-ías rapidamente, quando retornarem condições mais adequadas (HENCKEL, 1970). Em geral, a divisão celular parece ser menos afeta da pelos déficits de água que a expansão celular̄ (SLATYER, 1967). Isto poderia proporcionar razões de crescimento mais rápidas em plantas reumideci das, após estarem submetidas a um deficit, que em plantas adequadamente irrigadas. Dessa maneira, os efeitos do deficit poderiam ser parcial ou totalmente recuperados em um estadio subsequente, con forme tem sido observado em plantas novas de toma= teiro (GATES, 1955a), beterraba açucareira (OWEN \& WATSON, 1956) e milho (ACEVEDO et al., 1971). A atenuação dos efeitos prejudiciais poderia contribuir significativamente para aumentar a eficiência de utilização de ãgua pelas plantas.

Conforme acentuou GATES (1968) o papel da ăgua na célula não pode ser considerado apenas como sen do passivo. Existem inümeras experiências que eví denciam sua participação nas funções e estruturas protoplasmáticas. A estabilidade do protoplasma não depende apenas do grau de hidratação da célula, mas também, da manutenção de centros especificos de ligações da ãgua em pontos definidos na estrutura macromolecular. VAADIA et al. (1961) enfa tizaram o estudo das relações entre os déficits dé água e o metabolismo, e a maneira pela qual a redu ção do potencial da água influencia a velocidadē das reações e induz substitulções no modelo fisiológico dos tecidos vegetais.

No presente trabalho foi observado o crescimen to de plantas de batata, em condições de campo-, quando submetidas a três regimes de umidade do solo durante três estádios fenológicos. 


\section{MATERIAL E MÉTODOS}

Este trabalho foi realizado em Botucatu, Estado de São Paulo, em um solo classificado como um Latosol Vermelho-Escuro fase arenosa, Série Experi mental. Para tanto, desenvolveu-se uma cultura de batata (Solanum tuberosum L., varied. Bintje) adotando-se um espaçamento de $30 \mathrm{~cm}$ entre as plantas e $80 \mathrm{~cm}$ entre as linhas de plantio. A adubação de pré-plantio foi calculada à razão de $60-300-200 \mathrm{~kg}$ por hectare, de $\mathrm{N}, \mathrm{P}_{2} \mathrm{O}_{5}$ e $\mathrm{K}_{2} \mathrm{O}$, respectivamente. Aos 52 dias após o plantio, por ocasião da amontoa, fo ram aplicados $120 \mathrm{~kg}$ de $\mathrm{N}$ por hectare, em cobertu= ra.

Utilizou-se um delineamento experimental em blocos ao acaso, com nove tratamentos e quatro repetições. Os tratamentos basearam-se em três regi mes de umidade do solo impostos em três estádios fenológicos, conforme anotado na Tabela 1 .

o plantio realizou-se em 30 de abril de 1973.A duração de cada estádio foi determinada pelo inter valo de tempo necessário para o potencial atingir $-5,0$ bares nos tratamentos implicados.

o momento de se proceder as irrigações era indicado por tensiômetros $(-0,5$ bar) e blocos de ges so de resistência elétrica $(-1,0$ e $-5,0$ bares) pree viamente calibrados (TAYLOR, 1955). A água foi aplicada em sulcos fechados e nivelados. Para asse gurar a manutenção dos regimes de umidade preconi= zados, a área experimental era protegida por uma lâmina de plástico transparente, por ocasião das chuvas.

O crescimento das plantas foi estimado em base semanal, empregando-se o método por EPSTEIN \& ROBINSON (1965). Os estudos de correlação desenvolvidos paralelamente ao experimento de campo, apresentaram a seguinte equação para esta estimativa:

$$
A=0,3288 c^{1,1385} \quad r=0,88 * *
$$


onde $A$ é a área foliar em $\mathrm{cm}^{2}$ e $c$, o comprimento da folha, em $\mathrm{mm}$, medido desde a base do pecíolo até a base do limbo do folíolo apical. E conveniente sa lientar que em todas as determinações desenvolvi= das durante o ciclo fenológico o tratamento $A$, no primeiro estádio, representa também os tratamentos F, G, H e I; O tratamento B inclui o D e, o tratamento $C$ refere-se também ao $\mathrm{E}$. No segundo estádio, - tratamento A é participado também pelos tratamen tos $\mathrm{H}$ e I. Ao adotar este critério, pretendeu-sé aumentar a representatividade dos valores obtidos devido ao maior número de repetições disponiveis nas diversas determinações.

Tabela 1 - Potencial matricial da água do solo (bares) antes de cada irrigação. Valores médios para $30 \mathrm{~cm}$ de profundidade.

\begin{tabular}{cccc}
\hline Tratamento & 10 estädio & 20 estädio & 39 estädio \\
\hline A & $-0,5$ & $-0,5$ & $-0,5$ \\
B & $-1,0$ & $-1,0$ & $-1,0$ \\
C & $-5,0$ & $-5,0$ & $-5,0$ \\
D & $-1,0$ & $-0,5$ & $-0,5$ \\
E & $-5,0$ & $-0,5$ & $-0,5$ \\
F & $-0,5$ & $-1,0$ & $-0,5$ \\
G & $-0,5$ & $-5,0$ & $-0,5$ \\
H & $-0,5$ & $-0,5$ & $-1,0$ \\
I & $-0,5$ & $-0,5$ & $-5,0$ \\
& & & \\
\hline
\end{tabular}




\section{RESULTADOS E DISCUSSÃO}

As estimativas semanais da área foliar foram avaliadas em função daquela apresentada no início de cada estádio, à qual foi atribuída, arbitrariamente, o valor 1,0 (Figura 1 ). Os resultados foram identificados como a razão de crescimento rela tivo (RCR) das plantas em cada tratamento.

Em 15 de agosto, todas as plantas empregadas nas amostragens do tratamento I estavam mortas. Ao mesmo tempo, as plantas pertencentes aos demais tratamentos, principalmente $\circ C$ e $\circ G$, apresentavam-se em adiantado estado de senescência e, conse quentemente, as determinações foram encerradas.

Conforme pode ser observado, existe um períado de rápido crescimento vegetativo em seguida à emer gência das plantas que, com o passar do tempo, foí sendo progressivamente reduzido até estabilizar-se, cerca de 50 dias após a emergência. Nesta data as plantas caracterizavam-se por apresentar um grande número de tubérculos em desenvolvimento. HEDOU, (1965), baseado em MADEC \& PERENNEC (1962), admite que o crescimento e a tuberização constituem dois processos relativamente antagônicos. A tuberização parece ser induzida por alguma substância elaborada nas folhas. Assim, o processo será desencadeado quando esta atingir uma determinada quantidade ou concentração na planta. O tubérculo-semente geralmente contribui com alguma quantidade que, sendo muito elevada, ou se as condições ambientais favorecerem a intensa produção desta substância nas fo Ihas, o processo de tuberização poderá se tornar irreversivel e o crescimento paralizado. Em condi ções favoráveis para a maioria das variedades cul= tivadas, porém, ambos se processam simultâneamente. De qualquer maneira, segundo WASSINK \& STOLWIJK (1953), citados por LEOPOLD (1964) a tuberização pa rece reduzir o crescimento vegetativo das plantas da variedade Bintje, empregada neste trabalho. 


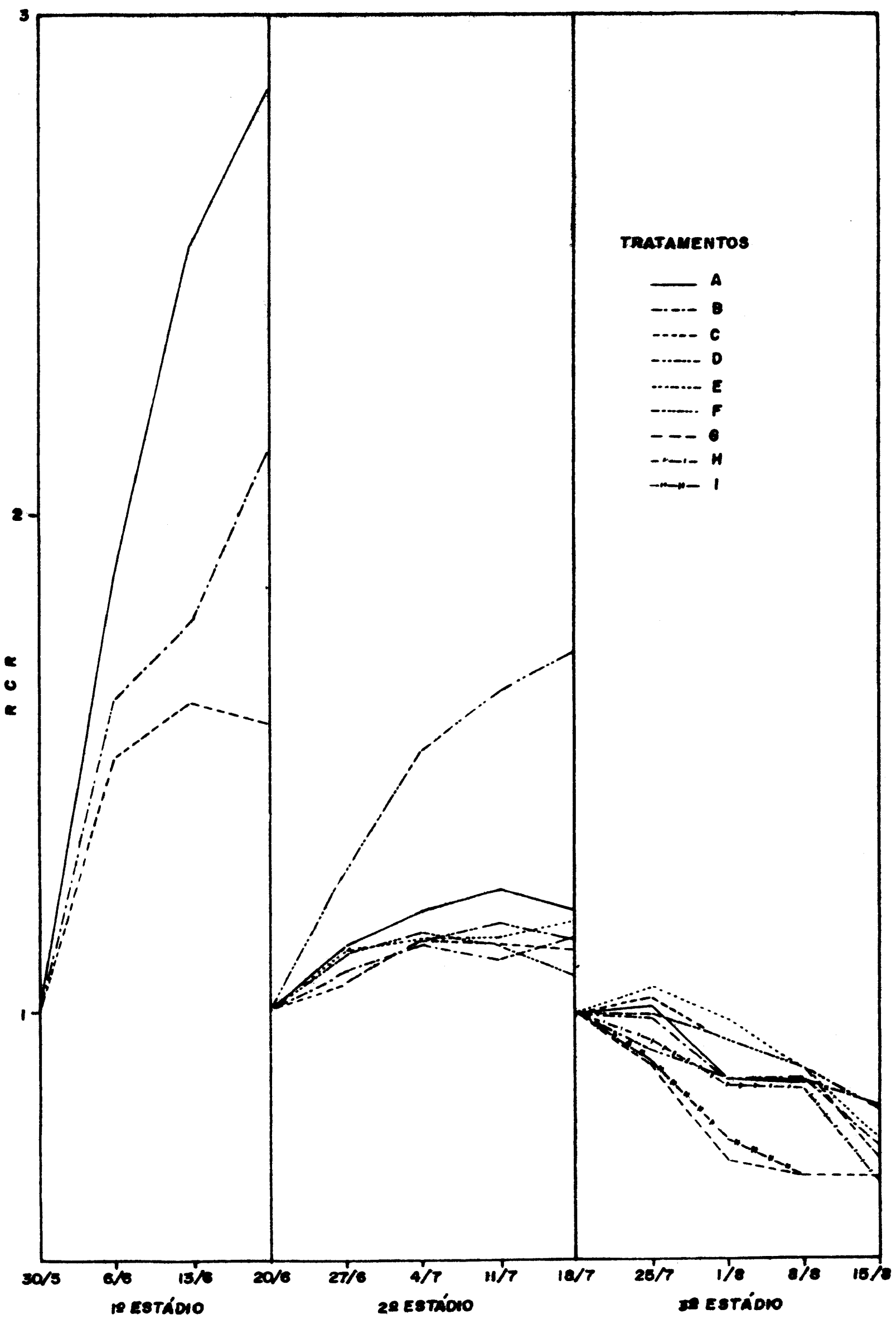

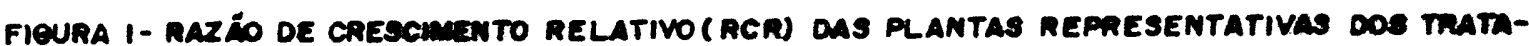

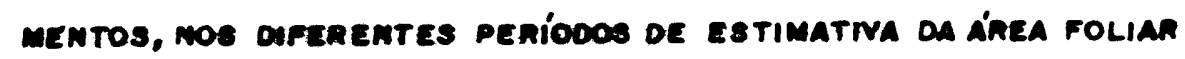


A influência do regime de umidade do solo na manifestação do crescimento pode ser apreciada, analisando-se os valores assumidos pela relação entre a razão de crescimento relativo do tratamento A e dos demais (Tabela 2).

o decréscimo da razão de crescimento no primei ro estádio foi, de certo modo, proporcional à redū ção do teor de umidade do solo. Assim, a RCR dō tratamento A mostrou-se cerca de $34 \%$ superior a do tratamento $B$ e, aproximadamente, 808 mais pronun ciada que aquela anotada para o tratamento $\mathrm{C}$.

A dependência do crescimento ao regime de umidade do solo tem sido frequentemente observada (STA NHILL, 1957; SLATYER, 1967，1969; BOYER, 1968; SHINN \& LEMON, 1968; RAWITZ, 1970). Segundo SLATYER (1963) o potencial da água do solo em contato com as raízes parece controlar, praticamente, o ní vel básico do potencial da água da planta e a pres são de turgescência. Consequentemente, todos os processos fisiológicos dependentes da grandeza des ses parâmetros deverão ser direta ou indiretamentē afetados pela redução do potencial da água do solo. A medida que o teor de umidade do solo diminui mai or deverá ser o intervalo de tempo para as folhas se recuperarem dos déficits hídricos suportados du rante o dia (GARDNER \& NIEMAN, 1964; SLATYER, 1967). Por outro lado, BOYER (1968) concluiu que os eleva dos potenciais da água requeridos para o crescimeñ to das folhas favoreciam o rápido crescimento fo= liar durante a noite e reduziam-no durante o dia. Assim, quando a umidade do solo diminui, os periodos de crescimento noturnos são reduzidos e o potencial da água da folha não se eleva suficiente mente. Além disso, o gradiente de potencial para a absorção de água torna-se menor, devido a redução do potencial da água do solo, e a pressão de turgescência não atinge o valor mínimo requerido para o crescimento. Mais recentemente, HSIAO (1973) baseado nos resultados de ORDIN (1960), ORDIN et al. (1956) e GREENWAY \& LEAHY (1970), considerou 


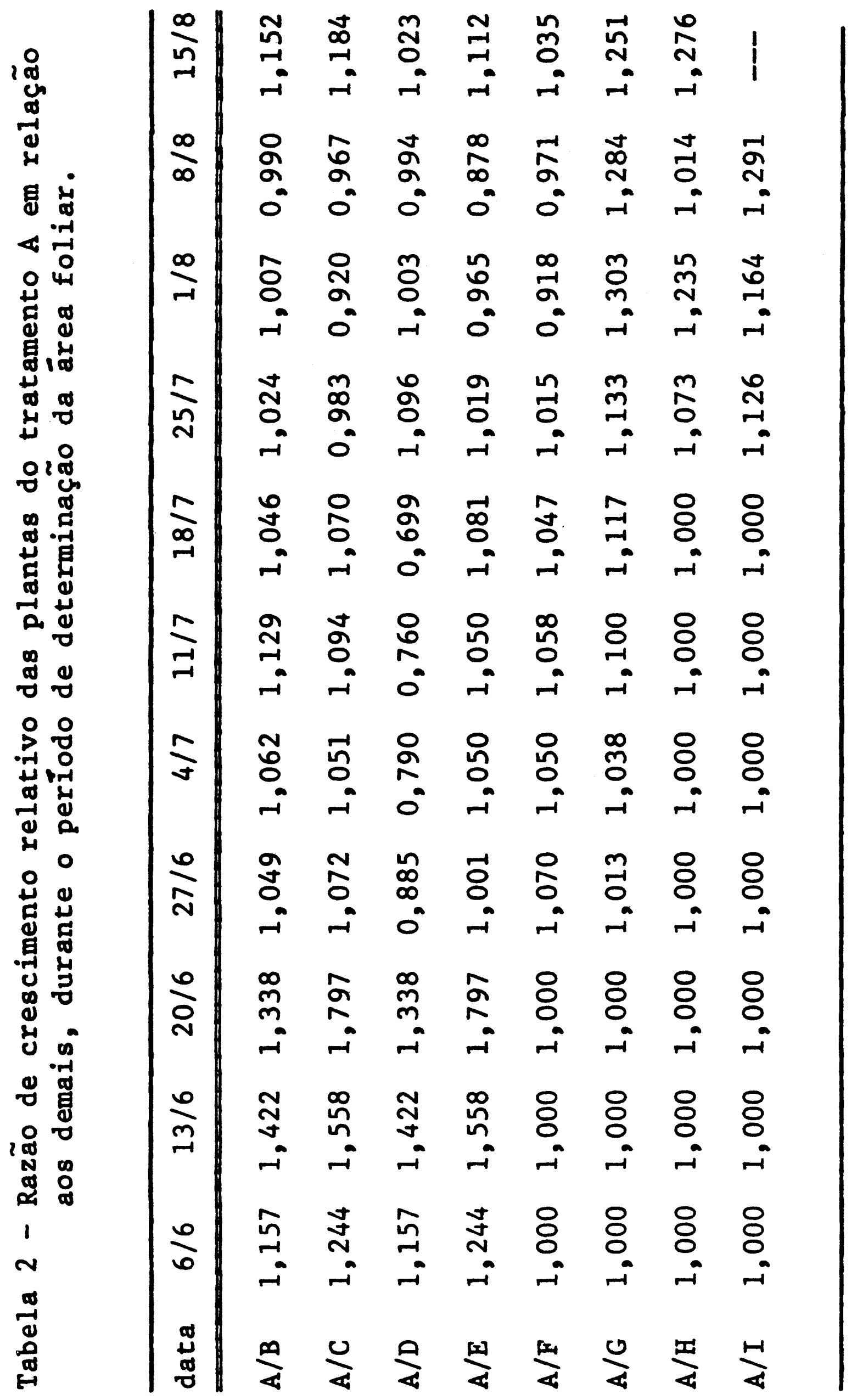


que a manutenção da turgescência é, provavelmente, um fator mais crítico na manifestação do crescimen to e outros processos metabólicos que os elevados valores do potencial da água da planta.

As revisões de GRAFTS (1968) levam à conclusão que as relações entre o potencial da água e o cres cimento das plantas são muito complexas, devido aō grande número de processos fisiológicos que parecem estar envolvidos. Além disso, estes processos são afetados em diferentes intensidades pela redução do potencial da água da planta. LEVITT (1972) admite que a habilidade da planta se desenvolver quando submetida a um déficit hídrico é limitada pelas propriedades do vacúolo e da parede celular. Assim, o máximo déficit hídrico no qual o cresci mento pode se manifestar aumenta com a pressão de turgescência e a plasticidade da parede das células.

Quando a redução gradativa do potencial da água do solo impõe déficits de água na planta, a in terferência no metabolismo deverá ocorrer, inicia I mente, apenas durante o período de máximo déficitét diurno. Este período torna-se mais amplo a cada dia, causando o fechamento estomático, que poderá reduzir a fotossintese e a transpiração, através do seu efeito nas trocas gasosas entre a folha e o ar atmosférico (SLATYER, 1967). Este autor admite ainda que a redução da turgescência poderá estar associada a um aumento da taxa respiratória, o que promoverá uma diminuição da razão fotossintética., afetando a razão de alargamento celular e, consequentemente, a expansão da área foliar. Todos estes fatores contribuirão para uma redução gradual da razão de crescimento.

- fato marcante no segundo estádio foi a rápida razão de crescimento do trabamento $D$, superando nitidamente aquela do tratamento A. Neste caso, a relação entre a RCR dos dois tratamentos foi sen do progressivamente reduzida, de tal maneira que 
ao final do periodo, a RCR das plantas do tratamen to $D$ excedeu em cerca de $30 \%$ àquela observada no traţamento A. A imposição de um déficit hídrico moderado durante o primeiro estádio pode ter contribuido para a manifestação deste comportamento.

Existem resultados experimentais mostrando que - alargamento celular pode ser mais sensivel à um reduzido potencial da ăgua da folha que a fotossín tese (VAADIA et al., 1961; BOYER, 1970). Assim, BOYER (1970) propôs que o alargamento celular de uma folha sob um reduzido valor de potencial não parece ser limitado pela falta de substâncias fotossintetizadas, a não ser que o déficit promova u ma translocação dessas substâncias para outras par tes da planta. Baseando-se nos resultados de GA= TES (1955a), MILLER (1965) e OWEN \& WATSON (1956), BOYER explica que durante déficits moderados, as substâncias fotossintetizadas deveriam ser acumula das na folha ou em outras partes da planta. Com es te acúmulo, o crescimento pode ser mais vigoroso após um período de deficiência de água, que anteriormente. Seus resultados observados em folhas de girassol submetidas a um potencial variável de $-4,0$ a $-9,0$ bares durante 4 dias, antes do solo ser reumidecido, parecem comprovar a tese apresentada. Entretanto, apesar do aumento da razão de crescimento, este não foi suficiente para propor cionar a completa recuperação em relação à testemu nha, o que evidencia a influência de algum outro fator limitando o crescimento, após o reumidecimen to. Um comportamento análogo pode ser observadō na Figura 1, examinando-se os dados obtidos no tra tamento D. Apesar da elevada razão de crescimentō apresentada no segundo estádio, a RCR acumulada ao final deste não superou aquela correspondente às plantas do tratamento $A$, concordando satisfatoriamente com a tese em pauta.

Resultados semelhantes foram obtidos por ACEVE Do et al. (1971), em folhas de milho. Estes autores observaram que embora o crescimento tenha sido severamente afetado por um déficit curto e modera- 
do $(-2,0$ bares na zona radicular) o efeito sobre o comprimento das folhas foi completamente recuperado pelo rápido crescimento temporário registrado após a eliminação do déficit, o que os levou a con cluir que os processos metabólicos necessários $\bar{a}$ expansão celular, aparentemente, não foram afetados durante o período desfavorável.

SLATYER (1969) baseia-se na contínua divisão celular das plantas sob um déficit hídrico, embora à uma razão mais reduzida (GARDNER \& NIEMAN, 1964) para justificar a rápida recuperação do crescimento quando as condições favoráveis são restabelecidas.

O tratamento $E$, submetido a um déficit mais se vero durante o primeiro estádio, não revelou o mes mo comportamento apresentado pelo tratamento $\mathrm{D}, \mathrm{a}=$ pesar de estarem submetidos às mesmas condições de umidade do solo no segundo estádio. Segundo SLATYER (1967) a ocorrência de um déficit mais severo pode conduzir à completa desarticulação de muitos processos fisiológicos relacionados ao crescimento. Além disso, baseado nas considerações de HEDOU (1965) é provável que nestas condições a tuberização tenha se manifestado, provocando uma severa li mitação ao crescimento. Isto pode ser válido desde que se admita que os dois processos sejam relativamente antagônicos.

A ocorrência de déficits hídricos mais severos durante o período caracterizado pelo desenvolvimen to de um grande número de tubérculos (tratamento $\bar{C}$ e G no segundo estádio e, C e I, no terceiro) contribuiu para antecipar a senescência das plantas. Este fenômeno foi observado tambēm em tomateiro (GATES, $1955 \mathrm{a}, \mathrm{b}$ ). Os processos envolvidos parecem ser de natureza irreversível, uma vez que a restituição de um regime de água mais adequado em seguida ao déficit não foi efetiva para retardar seu desenvolvimento, conforme pode se observar no tratamento G. A manifestação da precocidade em função do regime de umidade do solo poderia se 
constituir em um comportamento desejável, desde que a produção não seja significativamente afetada em decorrência da imposição dos déficits hídricos.

\section{CONCLUSÕES}

o crescimento de plantas de batata se mostrou acentuadamente dependente da grandeza do potencial matricial da água do solo antes de se proceder as irrigações- Assim, a ocorrência de potenciais até $-1,0$ bar e $-5,0$ bares, no período inicial de desen volvimento, provocou uma redução no crescimento vê getativo de, respectivamente, $34 \%$ e $80 \%$. O restabelecimento de condições mais adequadas de umidade no estádio subsequente promoveu uma recuperação par cial do crescimento, nas plantas sujeitas à défi= cits moderados no estádio inicial. Ocorrendo défi cits mais severos neste estádio, porém, a razão dé crescimento não conseguiu reassumir valores significativos.

Conforme ficou evidenciado, os processos que determinam o crescimento das plantas de batata parecem ser afetados desigualmente pela redução da umidade do solo. Dependendo da intensidade e dura ção dos déficits hídricos, a razão de crescimento poderá ser restabelecida e a senescência antecipada. Estes fenômenos, criteriosamente associados à produção de tubérculos, poderiam ser considerados quando se objetivar o aumento da eficiência de uti lização de ãgua pelas plantas em culturas irrigadas.

SUMMARY

\section{RELATIONSHIPS BETWEEN PLANT GROWTH} AND MOISTURE LEVELS IN THE SOIL

Plant production is a result of manu integrate physiological processes which occur during growing season. Whathever those processes show considerable individuality 
with relation to environment. In this work the vegetative growth of potato plants (Solanum tuberosum L.) growing in the field was observed for three soil moisture regimes in three growth stages. The vegetative growth was evaluated through leaf area estimate in weakly basis.

The results showed that by the ending of the first growth stage (about 25 days after plant emergency) the vegetative growth in the treatment where soil water matric potential never dropped less than -0.5 bar, exceeded in about 34 percent that observed for plants submitted to moderate water deficits $(-1.0$ bar), and in about 80 percent for those submitted to more severe water deficits ( 5.0 bars). However, the inhibition of vegetative growth in the first treatment was partially recovered after the re-establishment of suitable soil water condition.

Occuring more severe water deficits in the initial growth stage, recovering of normal rates of vegetative growth did not occur upon rewatering. Intensive soil water depletion after complete vegetative growth hastenned plant senescence when compared with plants growing in well watered soils.

\section{BIBLIOGRAFIA CITADA}

ACEVEDO, E.; HASIAO, T.C.; HENDERSON, D.W., 1971. Immediate and subsequent growth responses of maize leaves to changes in water status. P1. Physiol., Lancaster 48 (5): 631-636.

BOYER, J.S., 1968. Relationship of water potential to growth of leaves. P1. Physiol., Lancaster 43(7): 1056-1062 .

BOYER, J.S., 1970. Leaf enlargement and metabolic rates in corn, soybean, and sunflower at various leaf water potentials. P1. Physiol., Lancaster 46(2): 233-235.

CRAFTS, A.S., 1968. Water deficits and physiological processes. In, Koslowsky, T.T. (ed.), Water Deficits and Plant Growth (vol. II). New York, Academic Press, p.85-133 . 
EPSTEIN, E.; ROBINSON, R.R., 1965. A rapid method for determining leaf area of potato plants. Agron. J. 57(5): 515-516.

GARDNER, W.R.; NIEMAN, R.H., 1964. Lower limit of water availability to plants. Science, Was. 143(3613): 1460-1462 .

GATES, C.T., 1955a. The response of the young tomato plant to a brief period of water shortage. I. The whole plant and its principal parts. Aust. J. biol. Sci. 8(2): 196-21.4 .

GATES, C.T., 1955b. The response of the young tomato plant to a brief period of water shortage. II. The individual leaves. Aust. J. biol. Sci. 8(2): 215-230.

GATES, C.T., 1968. Water deficits and growth of herbaceous plants. In, Kozlowsky, T.T. (ed.), Water Deficits and Plant Growth (vol. II), New York, Academic Press, p. 135-190 .

HEDOU, M.J., 1965. Croissance et tubérization de la pomme de terre. Inst. Tech. de la Pomme de Terre 20, Paris, $30 \mathrm{p}$.

HENCKEL, P.A., 1970. Role of protein synthesis in drought resistance. Can. J. Bot. 48(6): 1235-1241.

HSIAO, T.C., 1973. Plant responses to water stress. A. Rev. P1. Physiol., 24: 519-570.

KRAMER, P.J., 1969. Plant and Soil Water Relationships: A Modern Synthesis. New York, McGraw-Hill Book Co, 482 p.

LEOPOLD, A.C., 1964. P1ant Growth and Development. New York, McGraw-Hill Book Co, 466 p.

LEVITT, J., 1972. Responses of Plants to Environmental

Stress. New York, Academic Press, 697 p.

OWEN, P.C.; WATSON, D.J., 1956. Effect on crop growth of rain after prolonged drought. Nature, Lond. $177(4514): 847$. 
RAWITZ, E., 1970. The dependence of growth rate and transpiration rate on plant and soil physical parameters under controlled conditions. Soil Sci. 110(3): 172-182.

SHINN, J.H.; LEMON, E.R., 1968. Photosynthesis under field conditions. XI. Soil-plant-water relations during drought stress in corn. Agron. J. 60(4): 337-343.

SLATYER, R.0., 1963. Climatic control of plant water relations. In, Evans, L.T. (ed.), Environmental Control of Plant Growth. New York, Academic Press, p. 33-34.

SLATYER, R.0., 1967. Plant-Water Relationship. New York, Academic Press, 366 p.

SLATYER, R.0., 1969. Physiological significance of internal water relations to crop yield. In, Eastin, J.D., Haskins, F.A., Sullivan, C.Y. e van Bavel, C.H.M. (ed.). Physiological Aspects of Crop Yield. Am. Soc. Agron., Crop Sci. Soc. Am., Madison, Wisc., p. 53-83.

STANHILL, G., 1957. The effect of differences in soil moisture status on plant growth: A review and analysis of soil moisture regime experiments. Soil Sci. 84: 205-214.

TAYLOR, S.A., 1955. Field determinations of soil moisture. Agric. Engng, St. Joseph, Mich. 36(10): 654-659.

VAADIA, Y.; RANEY, F.C.; HAGAN, R.M., 1961. Plant water deficits and physiological processes. A Rev. P1. Physiol. 12:265-292. 